\title{
Sand Bypassing Methodology For Sustainable River Mouth Opening
}

\author{
Blessan K Varghese, A S Kiran, Vijaya R, Suriyakala C D
}

\begin{abstract}
River inlets along the Tamil Nadu coast remain mostly closed due to negligible fresh water flow and also due to various structures constructed near to the river inlet obstructing natural sediment transport. Excessive development of the sand spit also causes serious problems such as water level rise during floods and difficulty in navigation through river mouth. To reduce the impact of coastal area flooding and easy navigation it is necessary to keep the river mouth open. River training walls (RTW) are generally constructed to keep the river mouth open. Depending upon the sediment transport direction, sediments get deposited on one side of the RTW, while depleting the sediments from the other side.

To prevent the sediment deposit from spilling over to river mouth, it is ideal to bypass the sand to the other side of the river mouth. This study analyses the methodologies for sand bypassing. A numerical model study has been carried out using DHI LITPACK to evaluate the sedimentation. The procedure of sand bypassing using pumps and pipe lines are discussed. Volume of sand bypassed, pump capacity, the number of Booster pumps to maintain critical velocity etc. can be determined based on the procedure discussed.
\end{abstract}

Index Terms:mouth closure, LITPACK, sustainable inlet opening.

\section{INTRODUCTION}

River mouth morphology is affected by longshore currents and out flow from the rivers. River mouth closure is caused by formation of sand spit under the conditions of a strong longshore current and low outflow from the river. This sandy deposit builds up at the river mouth into a landform. Spit is connected to land and water body by either ends. Sand spits prevent waves and salt water from intruding into the river. Excessive development of the sand spit can cause serious problems like water level rising during floods, problems during fishing and difficulty in navigation. Longshore drifting is complemented by currents, which transport sediment through water along the side of coast [1]. These currents are set in motion by waves that hit the coast in an oblique angle, which causes littoral drift. When spits starts to grow, the water behind them is sheltered from wind, waves,

Revised Version Manuscript Received on 10 September, 2019.

Blessan K Varghese, School of Ocean Engineering and Underwater Technology, Kerala University of Fisheries and Ocean Studies , Kochi, Kerala, India.

(Email: blessan.k.v@gmail.com)

A S Kiran, Coastal and Harbour Engineering, National Institute of Ocean Technology, Chennai, Tamilnadu, India.

(Email: kiran@niot.res.in)

Vijaya R, Coastal and Harbour Engineering, National Institute of Ocean Technology, Chennai, Tamilnadu, India.

(Email: vijaya@niot.res.in)

Suriyakala C D, School of Ocean Engineering and Underwater Technology, Kerala University of Fisheries and Ocean Studies, Kochi, Kerala, India,

(Email: drcdsk@yahoo.in) and a salt marsh is likely to develop. To maintain an open river mouth, it is important to understand the morphology behavior in response to waves, tides, river flow and the construction of structures around a river mouth [1], [2]. In India several river mouths face such issues. Sand bypassing systems, dredging, construction of various structures like river training walls etc. are some methods adopted to tackle river mouth closure issue [3].

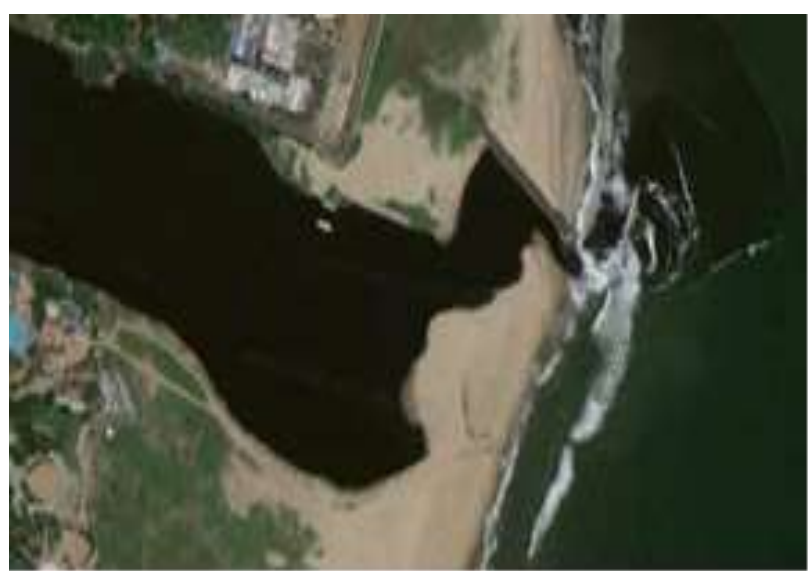

Fig. 1closed river inlet (Google earth image)

In this paper, procedures adopted for opening a river mouth is discussed. The amount of sediment to be removed is determined by using DHI LITPACK. The bypassing methodology is discussed for transferring the volume of sand blocked at the river inlet.

\section{METHODOLOGY}

The methodology for the quantification of blocked sediments and sand bypassing system design are discussed below.

\section{A. LITPACK}

LITPACK is a deterministic method of numerical modeling system, describing the major processes in the near shore zone. LITPACK integrates DHI's proven numerical models for coastal sediment transport and coastline development, in a single package suitable for a wide range of coastal engineering applications [4]. The individual modules of LITPACK simulate particular coastal processes, the links between each modules being performed by an automatic control module [4]. This can produce rapid simulation of complex coastal problems, with-out loss of detail in the individual modules.

\section{Published By:}

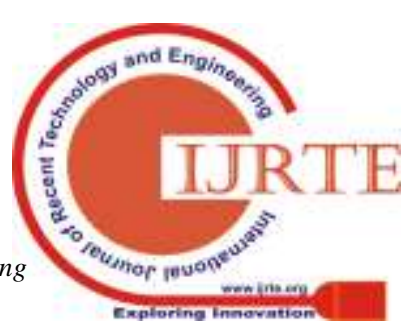


All LITPACK modules apply a fully deterministic approach. This allows to consider several factors including dominating factors which are not available to semi-empirical formulations. For example the simulation of a complex multi-barred profile with varying grain size distribution is prone to gross error when using an energy flux approach but it is easily included in LITPACK. The processes covered by the individual modules can broadly be described as: [4]

Table 1: LITPACK engines [4]

\begin{tabular}{|l|l|}
\hline LITSTP & $\begin{array}{l}\text { Non-cohesive sediment transport in one } \\
\text { point by combined waves and currents }\end{array}$ \\
\hline LITDRIFT & Longshore current and littoral drift \\
\hline LITLINE & Coastline evolution \\
\hline LITTREN & Trench sedimentation \\
\hline LITPROF & Cross-shore profile development \\
\hline
\end{tabular}

\section{MODELLING USING LITPACK SOFTWARE}

LITDRIFT engine of LITPACK can be used for the modeling purpose. The input data required for modeling are given below.

\section{A. Bathymetry}

In LITPACK it is assumed that the coast line is quasi-uniform, i.e. the bottom contours are almost parallel to the coast. This way the hydro dynamics (longshore current and wave variation across the profile) can be calculated in one dimension (profile normal to the depth contours) as if the current is fully developed and no disturbances in the bathymetry are present in the longshore direction. The cross shore profile in LITPACK is described by a line series data file (one dimensional grid) containing the bathymetry level perpendicular to 6the coast line in a number of equidistant grid points

\section{B. Sediment Properties}

The sediment properties must be defined for each grid point in the cross-shore profile. It includes the variation of the sediment size (usually the sediment size will become finer with increasing depths). It is preferable to collect sediment samples at a number of positions across the profile where sediment transport is expected to occur (i.e. from the beach line out to deeper waters). The values are obtained from the D50 values of collected samples from the site spectral description, spreading factor, current speed, Ref. No for current, wind speed, wind direction and wind friction coefficient.

\section{Wave Climate}

In LITDRIFT and LITLINE the main input parameters for the hydraulic computations are the: wave height, wave angle and wave period for a given depth in the profile.

\section{Profile Description}

A cross-shore profile is described by a line series file with 5 items, like bathymetry, roughness, mean grain diameter, fall velocity and geometrical spreading. All these values are obtained from the field measurements. The format of the profile depends on program which is used (LIT- DRIFT and LINTABL). In LITLINE only the first two items mentioned above are used. All calculations related to the characteristics of the sediment are performed in LINTABL [4].

\section{E. Climatic Description}

The LITPACK wave climate file is described by a time series file that contains 15 items, describing the hydrodynamic conditions. Those are duration, wave height, wave direction, profile number, wave period, Ref.depth (height), Ref. Depth (angle), mean water level, spectral description, spreading factor, current speed, Ref. No for current, wind speed, wind direction and wind friction coefficient.

\section{PROCEDURE \& RESULTS}

\section{A. Estimation of sediment deposit}

The LITDRIFT engine provides the net and gross sediment transport rate across a given cross shore profile, sediment data and wave characteristics. LITDRIFT engine is used to determine the sediment deposition on the south of river training wall structure. For this the sediment transport rates are obtained from model run with and without structure. The difference in the sediment transport rates will give the quantity of deposition. The model results can be calibrated and validated using field measurements. The typical profiles with and without structure are shown in figure. Once the quantity of sediment deposition is known, method to bypass it can be designed

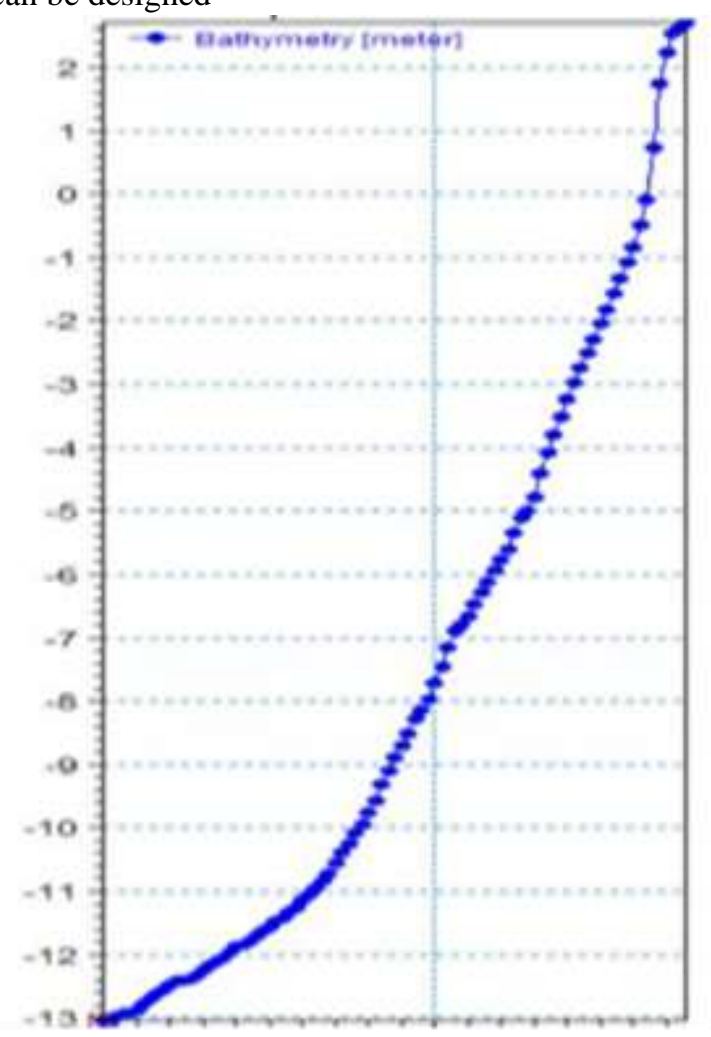

Fig. 2 cross shore profile without structures 


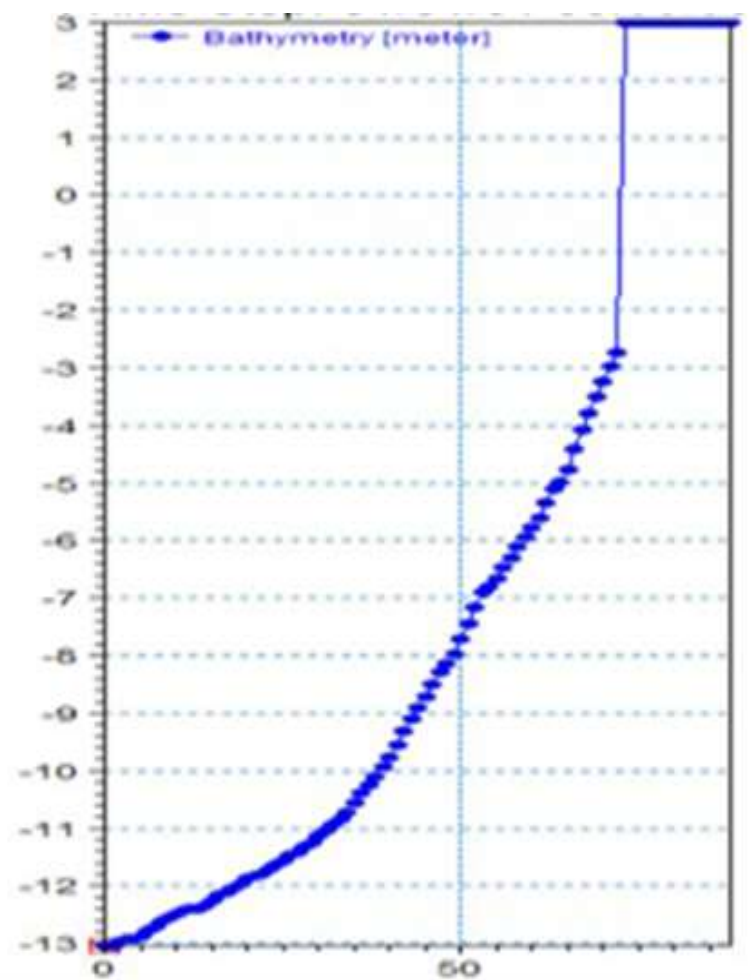

Fig.3 Cross shore profile with structure

\section{B. SAND BYPASSING}

Sand bypass system is a permanent or temporary solution to sand erosion and littoral drift problems affecting river mouth and navigation channels worldwide. The solutions include different types of bypassing methods. They are [5]

1 Dredging (using dredger or barge combinations)

2 slurry pump and pipe lines

\section{DREDGING}

Dredging is an activity carried out underwater, in shallow seas or fresh water areas for excavating bottom sediments and disposing them at different location. Dredging is done to maintain depth in existing ports, harbours and channels, to create new or deeper channels or berths for vessels, to construct new structure inside water bodies, to remove blocked sediments etc. [6]. Dredged materials are also used for beach nourishment so as to protect beach from erosion. Dredging can be classified mainly as capital dredging and maintenance dredging. In capital dredging previously undisturbed natural soil or rocks are removed. It is usually done with cutter suction dredger or trailing suction hopper dredger. For maintenance dredging, sediments that are accumulated in basins, existing channels and pockets are removed. It is usually carried out using trailing suction hopper dredger [6].

Dredgers can be classified as hydraulic dredger and mechanical dredger. There are many other dredgers available such as bucket dredger, grab dredger, cutter suction dredgers etc. The selection of dredgers is based on the type of soil or rock to be dredged. Mechanical dredgers usually use heavy equipment which is usually brought in on a barge to excavate the bottom sediments. While hydraulic dredgers suck up and filter the bottom sediments. It mainly removes loosely compacted materials while mechanical dredgers remove both loose and hard compacted material.

Barge is used in dredging for loading and transporting dredged materials to disposal site. Barge is a vessel which holds dredgers and self-propelled barges sails to the deposit area so as to unload dredged material.

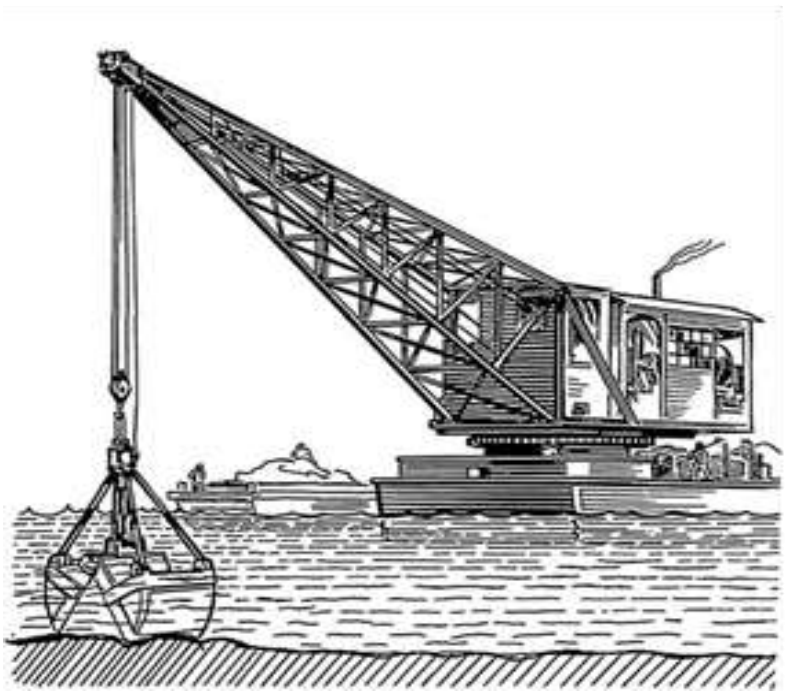

Fig. 4 Dredging [4]

\section{SLURRY PUMP AND PIPELINES}

Coastal erosions is a serious threat to coastal areas. The sand bypassing systems are great option to restore, the coast partially or fully. There are different types of sand bypassing systems [5] that are classified mainly based on the following

\section{(a) Purpose}

Based on purpose there are two types of sand bypassing systems, one is natural sand bypassing system like natural sandspits or sand bars which naturally bypasses the sand and the other is artificial sand bypassing.

\section{(b) Mobility/flexibility}

Sand bypassing systems have been developed artificially for carrying out maintenance activities. In mobile systems the entire physical plant can be moved and relocated but in the fixed systems they are those in which entire bypassing plant has a fixed location and such systems require high predictability of littoral transport.

\section{(c) Operating mode}

Based on the operating mode the sand bypassing system is classified into interception and storage areas. In interception mode systems they usually capture only a portion of the littoral drift and they may not able to handle the sediment influx in the maximum littoral drift periods.

\section{(d) Operating schedule}

The sand bypassing system can operate either continuously or on a periodic basis. In continuous type it aims to substitute natural sediment transport along the coast by assuring permanent bypassing.

Periodic or discontinuous systems are the systems which usually operate only when bypassing is necessary or a critical point is reached

\section{Published By:}

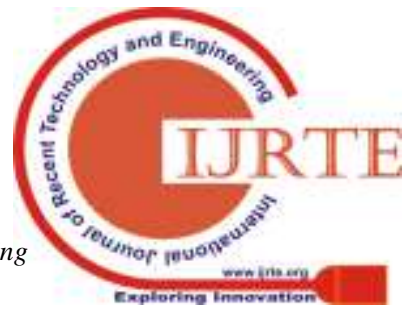




\section{(e) Capacity}

The amount of sand bypassed across the inlet is one of the most important parameter in the design of sand bypassing system. So the systems are classified based on the capacity of the system.

\section{Design of Sand Bypassing System}

A sand bypassing system which is designed to transfer a particular volume of sediment from a river inlet to a distance within specified days is discussed.

Different slurry pumps are available in market which can be used for sand bypassing. Based on the volume of sand required to be bypassed and distance of bypassing, the pump has to be selected. For the effective and efficient transfer of slurry without settling, it should have minimum velocity called settling velocity or critical velocity. This can be obtained from Durands limiting velocity diagram [7] corresponding to particle size in the slurry mixture, concentration by true volume and pipe diameter.

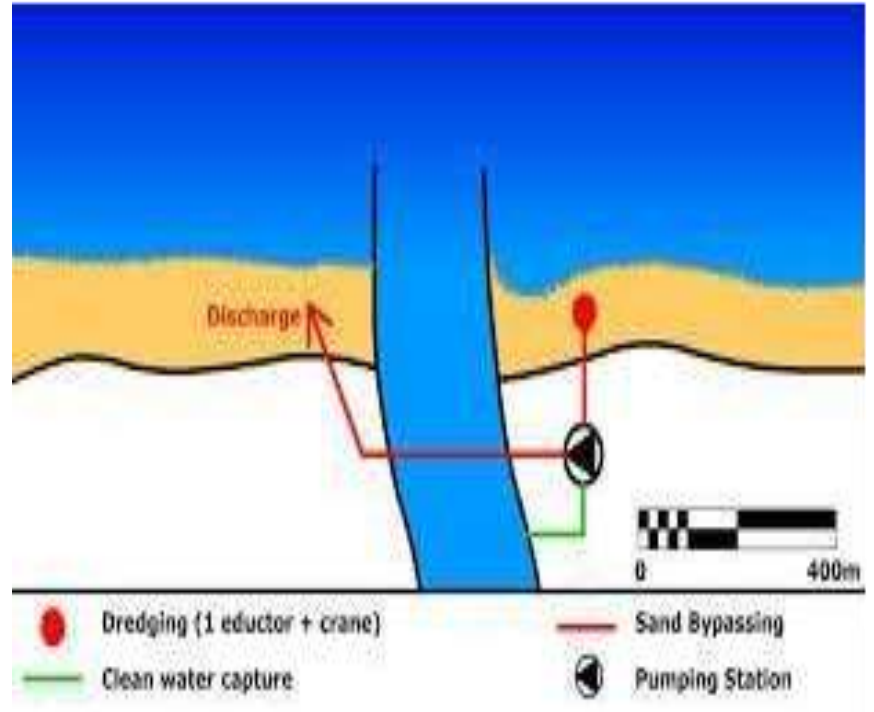

Fig. 5 sand bypassing system

The important parameters for the design of a sand bypassing system and the selection of the pump are

* Volume of excavation

* Distance to be transported

* Slurry density

* Pipe line specifications (friction and type of pipe used)

* Critical velocity

* Time availability for sand bypassing

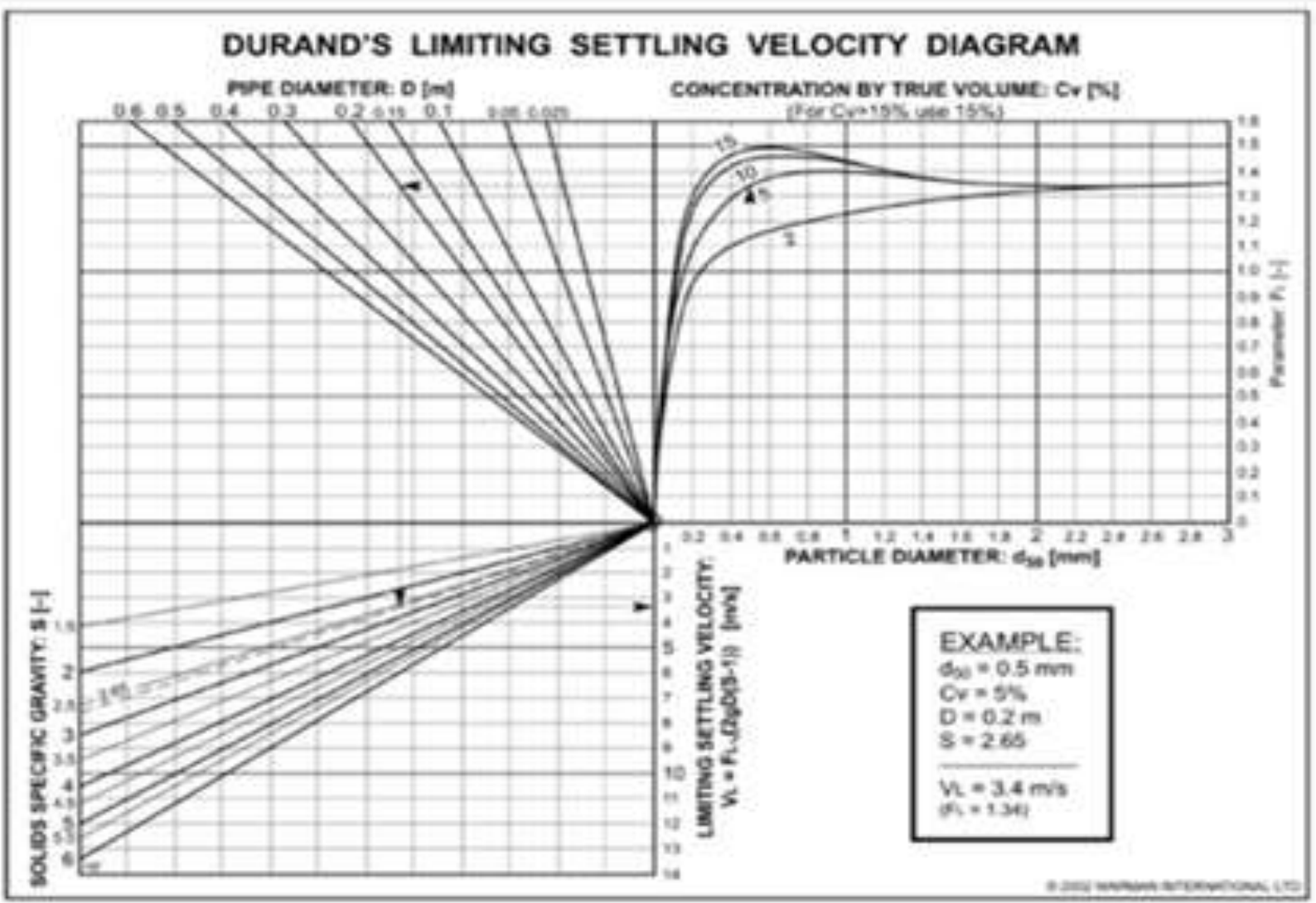

Fig 6: Durand's limiting velocity diagram

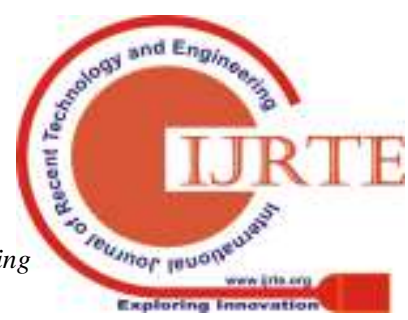


Where (friction head loss) $=$

Where $\mathrm{f}$ is the factor coefficient of friction

From the above equation length ( ) can be calculated for the

point at which velocity become critical velocity.

The above procedure can be adopted for designing sand bypassing systems using slurry pumps and pipelines.

The properties of slurry density, viscosity, flow rate, concentration of solid by volume and mass in percentage are calculated analytically. By using the properties of slurry, the required pipe size, pump etc. can be designed. The ratio of quantity of sediments to be bypassed to time gives the discharge rate. Pumps with suitable capacity and discharge can be selected for sand bypassing [7]. Equation of continuity is used to find the inlet velocity based on the required discharge.

In case of larger distances, it is convenient to provide booster pumps to avoid the settling of solid particles of slurry inside the pipe line. The location of booster pump can be determined by using the Bernoulli's equation with head loss [8][9]

\section{CONCLUSION}

River mouths are subjected to closure because of low inflow from the river and deposition of sediments by wave action. The amount of deposit depends on the littoral transport rates in the coast of interest. Any method to keep the river mouth open will be sustainable only if the quantity of sediments deposited is bypassed to the other side of river mouth either artificially or naturally. The natural method is removal of sediments into the sea by the flow of river. Artificial method includes dredging, bypassing using slurry pumps and pipeline etc.

River training walls are constructed to maintain the river mouth open. In such cases the sediments get deposited on the upstream side. Inorder to bypass these sediments to the downstream side, artificial methods of bypassing can be used. The procedure to estimate the quantity of deposition of sediments using LITPACK is discussed in detail. Also the procedure to design a sand bypassing system using slurry pumps and pipeline is provided.

\section{REFERENCES}

1. Kawamura, I. \& Tanaka, H.,"Recent Morphological Change at the Naruse River Mouth, Japan, International Conference on Estuaries and Coasts", 2016, Online https://www.researchgate.net/publication/237744951_RE CENT_MORP

HOLOGICAL_CHANGE_AT_THE_NARUSE_RIVER _MOUTH_JAP AN

2. EncyclopediaBritanica, Spit, 2016. Online.https://global.britannica.com/place/ Ishikari-River.

3. Black, K.P., Mathew, J., Anjali, S., 2017a. "The Maharashtra Shoreline Management Plan.Sanctuary Beach (Singapore), Sustainable Coastal ProtectionandManagement'Investment Program-Tranche 1.Maharashtra Maritime Board, Mumbai, India.

4. Danish Hydraulic Institute (DHI), 2014. User Manual and Reference Guide for LITPACKand MIKE 21.Horsholm, Denmark.

5. D M FitzGerald, N C Kraus, E B Hands,"natural mechanisams of sediment bypassing at tidel inlets",US
Army Cops of Engineers, ER DC/CHL, CHETN-IV-30, December 2000

6. WEDA (western dredging association), Journal of dredging", volume 16, No. 1,april 2018

7. Slurry pumps manual, First edition, 2002 WARMAN INTERNATIONAL LTD.

8. TOYO PUMP hand book,Toyo pumps India lnc.

9. E. C. McNair, Jr.,"A Sand Bypassing System Using A Jet Pump", Coastal Engineering 1976.

\section{AUTHORS PROFILE}

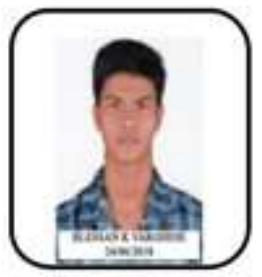

Blessan K Varghese Graduated in B.Tech Mechanical Engineering (2016), 2014 and pursuing M.tech in Coastal and Harbour Engineering from Kerala University of Fisheries and Ocean Studies, Kochi. With nearly six months of teaching experience.

Kiran A S Graduated in B.tech Civi Engineering from college of engineering, Trivandrum (2007) and M.tech,in Geotechnical Engineering from IIT Roorkee (2009). Presently working as Scientist D at National Institute of Ocean Technology, Chennai. Has 9 years of experience in the area of Coastal Engineering. Involved in the design and execution of shore protection projects and execution of various sponsored projects in the area of Coastal Engineering.

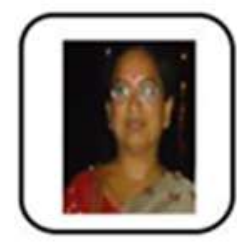

Dr. Vijaya Ravichandran, Scientist-F Coastal \& Environmental Engineering Group NIOT. Experience of over 25 years in Ocean related Civil and environmental engineering in coastal infrastructure development.Involved in design, development and deployment of suction pile in offshore waters. Design and field demonstration of submerged dyke using geosynthetics for river siltation prevention works in early 2003 in the Hugli Estuary and presently beach restoration in the Kadalur fishing villages - Tamilnadu

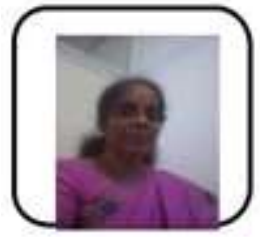

Dr. Suriyakala C D Graduated in B.E Electronics \& Communication Engineering 1990, M S (By Research) from Anna University Chennai and Doctoral degree from Sathyabama University in 2009. With nearly three decades of teaching experience, research experience, more than hundred publications and sponsored research projects added credits to her career. Editor \&Reviewer of premier journals. 